\title{
EVOLUÇÃO DE QUESTÕES E VERSATILIDADES DA COMUNICAÇÃO SOCIAL
}

\author{
EVOLUTION OF ISSUES AND VERSATILITIES OF SOCIAL COMMUNICATION
}

\section{Leonardo Moraes Armesto}

Instituto Brasileiro de Tecnologia Avançada, São Paulo, Brasil. E-mail: engenheiro.larmesto@gmail.com

\section{Patrícia Paiva Gonçalves Bispo}

Instituto Brasileiro de Tecnologia Avançada, São Paulo, Brasil. E-mail: profa.patricia.paiva@gmail.com

DOI: https://doi.org/10.46550/amormundi.v2i7.132

Recebido em: 12.11.2021

Aceito em: 28.12.2021

Resumo: $\mathrm{O}$ ambiente urbano, historicamente, é pactuante de uma sociedade necessitada de meios facilitadores das relaçóes e trocas. Essa premissa, desde sempre, tem o intuito da dominação do homem em relaçáo ao meio, e este último expressando, direta e indiretamente seu esgotamento frente à prática desenvolvimentista. Para tanto, a criatividade abjeta fora, ao longo do tempo, uma das ferramentas mais eficazes na variabilidade dessa conquista, e apresenta-se como fonte sólida de equivocada realidade. A busca por instrumentos e ferramentas de poder social que forjem o benefício pleno e perene é produto da reverberação de entidades e de pensadores do tempo presente, os quais são refletidos do passado e trampolins para ao futuro. Dada perspectiva é consonante com as agendas de ordem comunitária e vigorante em um preâmbulo onde o ser humano e a natureza fazem-se mutuamente e são sinergicamente, atores de um futuro tão comum quanto imprescindível.

Palavras-chave: Sociologia. Aprendizagem-significativa. Comunicação. Epistemologia. TICs.

Abstract: The urban environment, historically, is the covenant of a society in need of facilitating means of relationships and exchanges. This premise, since always, has the intention of the domination of man in relation to the environment, and the latter expressing, directly and indirectly, its exhaustion in the face of the developmentalist practice. To this end, the abject creativity had been, throughout time, one of the most effective tools in the variability of this conquest, and presents itself as a solid source of mistaken reality. The search for instruments and tools of social power that forge the full and perennial benefit is the product of the reverberation of entities and thinkers of the present time, which are reflections of the past and springboards for the future. Such a perspective is in line with the agendas of the community order, and in force in a preamble where human beings and nature are mutually and synergistically actors of a future that is as common as it is indispensable.

Keywords: Sociology. Significant Learning. Communication. Epistemology. TICs. 


\section{Introduçáo}

Se considerarmos a história do homem ao longo do tempo, podemos detectar, em $\checkmark$ vários momentos, o contato entre culturas como um fenômeno social que indica a sua diversidade de compreensão quando se considera a visão que um membro de certa civilização tem sobre aquele que difere de suas concepçôes, hábitos e costumes.

No mundo contemporâneo, o contato e a relação entre diferentes povos e culturas são, muitas vezes, exemplificados com casos de xenofobia, o que pode levar à crença de que a compreensão do "outro" é orientada pela questáo do conflito e da diferença. Contudo, principalmente no caso do trabalho dos professores com seus alunos, relação em pares sociais ou ainda em ambientes profissionais, de convivência e compartilhamento, essa questáo pode ser explanada e discutida com fundamento do outros prismas de visualização que tangem essa questão. Necessária a mostra e discussáo de que o contato entre culturas distintas pode, na grande maioria dos casos, salientar as diferenças que se estabelecem entre os povos sem, contudo, pensar simplesmente que o olhar sobre o "outro" vai sempre estar limitado à formulaçáo de afirmaçóes pré-concebidas ou a qualquer outro tipo de rebaixamento em sua legitimidade.

Esse processo é largamente revigorado com as mudanças no contexto, na época e no período. Para tanto, dada reformulaçáo é comungada pelos agentes que legitimam esse tempo, quer seja pela mostra de sua influência literalmente no âmbito político, ou ainda por meio de seu poder educacional, cultural e nos meios de comunicação. Dada expressividade ganhou uma série de palcos e instrumentalizaçóes ao longo do tempo, sendo fortalecida a partir da pósmodernidade e encarada com maior entusiasmo na contemporaneidade. Há, portanto, uma mescla significativa na formulação de instâncias que dão vazão as questôes sociais em aspectos que figuram o território, a globalização e as evoluçôes tecnológicas, como principais elementos de agravo do paradoxal desenvolvimento do espaço e do tempo. Se por um lado, proveu-se mais notoriedade e condiçóes ao debate dos paradigmas sociais, por outro, as redes tendem a dar falsa impressão da liberdade deliberativa da idéia e dos ideais, de forma a massificar e estratificar, polida e persuadidamente o coletivo social.

Neste sentido, cria-se o estereótipo que dá solidez e conforto á cátedra arraigada, enraizando o ideário, à medida que encena fluídica e eficazmente uma superfície pronta para a mudança e a desconstrução, na qual se liquefaz o desejo da ventilação e consolida-se mais do mesmo. Sua relevância vale-se pela busca do equilíbrio entre o uso tecnológico e a não fragmentação do usuário, bem como da maximização das questôes coletivas como meandro e ponte para a equidade social.

\section{Objetivo}

Definir o fundamento da cultura social como elemento de influências e determinaçóes proeminentes da contemporaneidade, à medida que o tempo evolui e os meios de comunicação consolidam-se mais tecnologicamente.

\section{Revisão de literatura}

No mundo contemporâneo, é cada vez mais convencional a utilização das TIC 
(Tecnologias de Informação e Comunicação), de maneira a ser possível detectar que, no contato entre grupos identificados por algumas características altamente visíveis, ativam-se algumas crenças associadas a esses grupos. Neste sentido, Leyens et al. (2000), ao analisar o início de um estudo de previsibilidade, salienta que a determinante que segmenta a forma com a qual a comunicação cria seu viés, não necessariamente exige grandes análises determinísticas. Neste sentido, consubstancialmente, o prefixo do endereço de um e-mail, indicando que o remetente era da nacionalidade dos participantes ou de outra nacionalidade, determinava o padrão da resposta. Especificamente, a resposta aos remetentes estrangeiros utilizava mais vocábulos traduzindo emoçôes infra-humanas do que vocábulos traduzindo emoçôes exclusivas do ser humano e o padrão inverso verificava-se quando o remetente era da mesma nacionalidade. (VIVANCO, 2015)

Para Otten et al. (1999), esse e outros estudos parecem indicar que o endogrupo e seus membros são automaticamente associados a sentimentos positivos e agradáveis e que o exogrupo e membros exogrupais são associados a sentimentos negativos e desagradáveis, mesmo quando a situação intergrupal é definida por critérios não controlados cognitivamente.

Essas discussões nos levam a pensar na imagem estereotipada que muitos indivíduos desenvolvem em suas relaçôes com "o outro". Em seu trabalho, Stroebe et al. (1989), descrevem que o termo "estereótipo" já existia desde 1798, sendo utilizado na tipografia, onde designava uma chapa de metal utilizada para produzir cópias repetidas do mesmo texto. Nas ciências sociais, o termo era utilizado para denotar algo "fixo" e "rígido", o que remete à origem etimológica da palavra stereo que, em grego, significa "sólido", "firme". Por analogia, Rigobello et al. (1998) salienta a "rigidez" das imagens mentais, especialmente aquelas que dizem respeito a grupos sociais com os quais temos pouco ou nenhum contato direto.

Muitos estudos posteriores caracterizaram a visão dos estereótipos como algo rígido sem, no entanto, como afirmava o autor, levar em conta a possibilidade de mudança dos estereótipos, salientando o caráter criativo da mente humana. Segundo Lippmann (2008), os estereótipos eram resultantes de um processo "normal" e "inevitável”, inerente à forma como processamos a informação. Entretanto, a maior parte dos estudos empíricos, realizados até a década de 1950, caracterizou os estereótipos como um tipo inferior de pensamento, situando-os no domínio do "patológico": estes estereótipos seriam projeçôes de fantasias indesejáveis, deslocamentos de tendências agressivas para os membros de outros grupos, ou subprodutos de síndromes de personalidade associadas ao autoritarismo e à intolerância.

Ao nos referirmos à discriminação social e às atitudes, vários trabalhos são encontrados na literatura. Histórica e inicialmente, Bogardus (1928), mostra o estudo sobre as "atitudes raciais" dos americanos durante uma época caracterizada por um grande fluxo migratório de grupos de origem asiática e européia para os Estados Unidos. Ele utilizou o que chamou, no trabalho, de Escala de Distância Social. O estudo revelou que os participantes rejeitavam, principalmente, os grupos de origem asiática e africana, preferindo os imigrantes de origem européia, principalmente os anglo-saxốes e os nórdicos. $\mathrm{Na}$ percepçáo de Arendt (2012), o preconceito em relação a grupos políticos (nazistas, socialistas, comunistas, etc.) tendo obtido, como resultado, que os indicadores de maior distância social foram obtidos pelos grupos políticos "extremistas" (nazistas, fascistas e comunistas), logo seguidos dos grupos étnicos minoritários - judeus, negros, turcos, árabes, chineses, hindus, mexicanos, imigrantes da Europa de Leste (romenos, russos, lituânios, 
etc.), e imigrantes da Europa Mediterrânea (gregos, italianos e portugueses). Mais uma vez, os imigrantes anglo-saxônicos e nórdicos (irlandeses, ingleses, alemães, dinamarqueses, etc.) apresentaram indicadores de menor distância social, sendo que o grupo ao qual pertenciam os sujeitos foi o único a ocupar o topo da escala.

Esses resultados demonstram que o preconceito não está diretamente ligado ao nível de conhecimento dos grupos-alvo em questão e são indicadores do caráter normativo da discriminação social nesta época, já que os participantes não hesitaram em discriminar, com base em um simples rótulo evocativo de minoria étnica.

$\mathrm{Na}$ ótica de Lima (2006) e Cabecinhas (2004), em diferentes estudos sobre atitudes, ficou demonstrado que, ao contrário do que se imaginava anteriormente, náo estava implícita a correlação entre atitudes e comportamentos ao se pressupor que as atitudes poderiam prever determinados padrôes de comportamento. Vários resultados mostraram que é possível haver uma manifestação de tolerância ao nível comportamental e, simultaneamente, uma expressão de intolerância ao nível atitudinal, que permitiram sua interpretação como reflexo de uma inconsistência entre atitudes e comportamentos.

Se os estereótipos culturais existem, mas não estão na cabeça de ninguém, ou de quase ninguém, onde se encontram? E se não estão na cabeça das pessoas "não preconceituosas" porque estas têm que ter energia mental disponível e motivação para não se deixar influenciar por eles?

Na perspectiva de Cabecinhas (2002), os resultados de diversos estudos indicam crenças pessoais mais positivas do que os estereótipos sociais, assim como os estudos que indicam que as pessoas geralmente se consideram menos racistas do que a média das pessoas do grupo a que pertencem. Esse fato pode ser interpretado como uma manifestação do efeito Primus Inter Pares, na perspectiva de Codol (1975). Conhecendo as normas sociais de não discriminação, os indivíduos tendem a apresentar-se de forma mais consonante com essas normas do que os restantes membros da sociedade em que se encontram o que consiste em uma forma de obter distinção pessoal através da adesão a normas socialmente valorizadas.

Outra questão que merece ser abordada é o papel das TIC (Tecnologias de Informação e Comunicação) na sociedade contemporânea. De acordo com Perregil et al. (2020) e Ramos (2009), na área educacional, a popularização das TIC levou o computador às escolas como ferramenta de ensino e de aprendizagem. Sua versatilidade e convergência midiática exercem grande fascínio sobre os educandos, já que também está presente em suas práticas sociais. A utilizaçáo de jogos, a possibilidade de digitação de textos, o uso de salas de bate-papo e participação em redes sociais representam essa prática que, na escola, se transpóe para o uso de softwares, jogos educativos, enciclopédias virtuais e pesquisas em sites da Internet. Para Guimarães et al. (2018) essa é uma realidade que se apresenta em grande expansão e que tem sido amplamente aceita pela sociedade, sendo vista como uma oportunidade de eliminar diferenças e fomentar oportunidades de trabalho. Entretanto, pode-se afirmar que a utilização das novas tecnologias pode não resultar, necessariamente, em ganhos lineares, já que a capacidade que as TIC possuem para transmitir e multiplicar informaçóes esbarra na condição dos que possuem acesso a esses recursos e dos que são excluídos. (NOBRE et al., 2021)

Conforme Schaff (1995), na sociedade informatizada, a ciência pode assumir o papel de força produtiva e assim, produzir novas divisóes de classe e novas diferenças sociais entre as pessoas, de forma a produzir uma nova divisão entre as pessoas, a saber: uma divisão entre as que 
têm algo que é socialmente importante e as que não têm. Este "algo", no caso, é a informação no sentido mais amplo do termo que, em certas condiçóes, pode substituir a propriedade dos meios de produção como fator discriminante da nova divisão social, uma divisão semelhante, mas não idêntica, à atual subdivisão em classes.

Em um mundo globalizado, onde as pessoas se comunicam e interagem em tempo real graças às novas tecnologias, não se pode deixar de levantar algumas questôes sobre as alteraçóes produzidas na forma como trabalhamos, como nos relacionamos uns com os outros, como desfrutamos os momentos de lazer, como entendemos o que nos rodeia.

Segundo Ilharco (2009), o que mais muda pode, atualmente, ser testemunha do mundo dos mais novos, no mundo onde as crianças e os adolescentes de hoje, os homens e as mulheres de amanhã, vivem eletronicamente, tanto em Portugal ou no resto da Europa, como no Japão, em Xangai, nos Estados Unidos, em São Paulo ou na Austrália.

$\mathrm{O}$ ambiente eletrônico nos atinge de todos os lados e em enormes quantidades de som, de imagens, de textos, ou seja, de estímulos constantes, encoraja estruturalmente o equilíbrio sensorial, através da combinação dos vários sentidos humanos na visão de Ramalho (2012). $\mathrm{O}$ autor institui ainda que a disponibilidade, por parte dos nativos da era eletrônica, para um envolvimento sensorial mais profundo é respondida pelo modelo do livro, pelo menos de duas formas; na qual por um lado, os livros têm cada vez menos texto corrido e mais fotografias, legendas, gráficos, tabelas, desenhos, listas, cores. De mesma forma que por outro lado, a lógica de relacionamento dos leitores com os livros não é mais exclusivamente a de lê-los (o índice, o índex, os resumos, as palavras-chave, e também, as coleçôes, os rankings).

Da mesma forma, para Bellonni (2005) a informação tecnológica - o ambiente gerado pelas mídias eletrônicas - tende a substituir, virtual, metafórica e simbolicamente, isto é, realmente, a natureza. Nesse processo de substituição tecnológica, de atualização eletrônica constante, a lógica de entendimento, o fazer sentido da relevância, não é mais a da análise e da solução, mas a do padrão e da intuição. As alteraçôes no ambiente humano, promovidas pelas mídias eletrônicas, desencadeiam, em nós, novos modos de entendermos e de agirmos no dia a dia. Assim, a televisão a cabo, a Internet e os telefones celulares alteram, definitivamente, os modelos e padróes de percepção dos homens, introduzindo mudanças individuais e coletivas sem que haja qualquer tipo de compromisso ou de negociação.

O intenso envolvimento sensorial, produzido pela relação com as novas mídias, acaba refletindo no comportamento das crianças em seus primeiros momentos no ambiente escolar. Essas crianças “digitais", segundo McLuhan (1994) é possível descobrir que é muito difícil, senão mesmo impossível, ajustar-se aos objetivos fragmentados do sistema educativo literário, pelo fato de que, desde que nasceu terem os seus sentidos moldados pela eletrônica.

Não obstante, Ilharco (2009) traz ainda que, hoje, o real é o hiper-real. Para todos os efeitos, a quantidade de produtos e de serviços culturais é hoje infinita; e a sua qualidade, em geral e em termos massificados, deixa de boca aberta multidóes inteiras. O que enche as nossas vidas, os livros, os discos, os filmes, os milhares de aparelhos de eletrônica tem evoluído imensamente nos últimos anos; embora, claro, ao ser uma plastificação, uma substituição, e ao se experimentar como mais real que a realidade, a digitalização tem tido, como consequência, a subida dos preços e o desejo das elites por tecnologias não digitais, isto é, mais reais e menos hiper-reais. 
Em sinergia, Costa et al. (2003) entende que a evolução deste verdadeiro novo setor de atividade, a gigantesca área da informaçáo e comunicação, sucessora dos setores dos serviços e da velha indústria, e que nos chega como oferta cultural, tem feito sentir-se ao longo de três eixos, pautados no preço - consequência do quadro competitivo global em que se encontram as indústrias da informação, os preços evoluem em tendência estrutural de queda; na qualidade a digitalizaçáo, como que purificando aquilo que toca, tem permitido subidas significativas na qualidade dos produtos e serviços; e, finalmente, no resultado dos dois movimentos anteriores, entre outros fatores, a quantidade de produtos e de serviços do novo setor da informação e comunicação não para de subir.

Portanto, essa construção constante e desenfreada é multifacetada e capaz de interagir com o ambiente de forma a modelá-lo acerca de suas necessidades. Desta forma, cuidar da mobilidade comunicativa a fim de que esta contribua com o processo de melhoramento e reflexão se expressa como forma clara e estruturada de uma realidade funcional e contributiva no evolucionismo e versatilidade do ser humano e do meio.

\section{Metodologia}

Quando se busca uma forma de constituir um processo de mobilização social, os instrumentos de comunicação são parte fundamental da eficácia de dada iniciativa. Isto é, se bem fundamentados e usufruídos são capazes de contribuir de maneira inequívoca na produção de resultados assertivos daquilo que se pretende consolidar e transmitir informativa e analiticamente. Contudo, a busca dessa assimilaçáo perpassa pela forma com a qual seu usuário produz o uso dos instrumentos, bem como por sua experiência vivenciada e pactuada com os demais indivíduos que o margeiam.

Outrossim, a natureza avaliativa dos gentes históricos discursantes desse desenvolvimento e veiculação são alicerces fundamentais na construção do debate e da legitimidade metodológica do discurso e da vertente significativa da experiência comunicativa, de forma a figurar como prioritária forma de embasamento para o memorial material da aplicaçáo atual e da previsão futura.

Não obstante, por meio do instrumento literário, faz do ensino de historiografia da comunicação social, a esteira da fala e da reverberação, discursiva e interpretativa do ser humano em rede, bem como deste primeiro em contato com o ambiente natural. Essa estruturação é célere e constantemente substrato de reconstrução e reavaliação, onde as questôes sociais não são encaminhadas para respostas, mas para o refinamento de perguntas ainda mais profundas, substanciadas e consistentes com o avanço das necessidades e a descoberta de melhores formas na interface do sujeito e os desdobramentos de seus múltiplos saberes e sujeiçôes. Assim, em face de uma metodologia literária, é possível compreender a linha histórica, filosófica e cultural que globaliza os povos e que dinamiza suas relaçóes.

\section{Resultados}

O levantamento bibliográfico se faz em busca de confrontar tanto aspectos que colidem em sua referente contemporaneidade, quanto que diferem ou assemelham-se em momentos e 
movimentos históricos diferentes cronologicamente. Essa busca é capaz de formular detalhes importantes na interpretação dos fatos e na integração de realidades, molduras e simbologias que o processo evolucionista tratou de cruzar em conformaçóes globalizantes pelo mundo a fora.

A análise dos autores traça uma dinâmica que tipifica as lateralidades alcançadas pela versátil comunicação, e é consonante na idéia de que há cerca ambivalência no estreitamente da globalização e de seus povos, de forma a não necessariamente prover equidade de poderes, mas em acentuar as irregularidades seculares já vivenciadas por eles. Para tanto, há totalitarismo, estigma e manutenção do dogmatismo, além da ressignificação dos estereótipos e sua deflagração nos trejeitos mais comuns e arraigadas do coletivismo social. Para tanto, há distância na interpretação literária no que tange os caminhos de propagação dessa natureza. Contudo, tem-se em vista que as TICs possam afastar-se cada vez mais de uma uniformização, de forma a diversificar tanto sua transmissibilidade e seu alcance, quanto à majoração de emissores reais, historicamente oprimidos e legitimamente passíveis de voz e vez.

\section{Consideraçóes finais}

A capacidade de observação do momento presente, seja qual for o panorama histórico denotado naquele dado instante, é passível de entender como o contexto e dinâmica do coletivo funciona em termos de relação. Essa prática é capaz de dar suporte as tomadas de decisão que se fizerem necessárias para mudanças, ajustes ou descontinuidades. Para tanto, um olhar mais voltado para o outro, não cristalizando características e funcionalidades, é o instrumento de uma fala mais próxima e menos conflituosa. Dado limiar é cada vez mais vinculado as formas com as quais as TICs se apresentam no processo de disseminação e produção comunicativa. Assim, é factual a compreensão ambivalente desse panorama, de maneira que o equilíbrio entre o avanço das redes de informaçáo mais ampla no sentido de abranger a todos, dando aos diferentes sua devida diferença é fundamento chave para a validação do meio, dos recursos, da renovação e do ser humano legítimo e integral dessa e das demais contemporaneidades.

\section{Referências}

ARENDT, H. Origens do Totalitarismo [trad. Roberto Raposo] 1a ed. São Paulo. Companhia das Letras, 2012.

BELLONI, M. L. O que é Mídia-Educaçao. 2. ed. Campinas, SP: Autores Associados, 2005. (Coleçáo polêmica do nosso tempo, 78).

BOGARDUS, E. S. Race Attitudes. Cap. 2, p. 13-29. [In]: Immigration and Race Attitudes. Heath: Boston, D. C, 1928.

CABECINHAS, R. Media, etnocentrismo e estereótipos sociais. [In]: As Ciências da Comunicação na Viragem do Século. [In]: Atas do I Congresso de Ciências da Comunicação. Lisboa: Vega, p. 407-418, 2002. Disponível em: <http://repositorium.sdum.uminho.pt/ bitstream/1822/1599/1/racabecinhas_MedEtno_2002.pdf>; Acesso em: nov. 2021.

CABECINHAS, R. Processos cognitivos, cultura e estereótipos sociais. [In]: Atas do II Congresso Ibérico de Ciências da Comunicação, Universidade da Beira Interior, Covilhã, p. 
1-18, 2004. Disponível em: <https://repositorium.sdum.uminho.pt/bitstream/1822/1650/1/ rcabecinhas_II_Iberico_2004.pdf>; Acesso em: nov. 2021.

CODOL, J. P. Sobre o chamado comportamento de "conformidade superior do eu": Vinte investigaçóes experimentais. European Journal of Social Psychology, v. 5, n. 4, p. 457-501, 1975. Disponível em: <https://onlinelibrary.wiley.com/doi/abs/10.1002/ ejsp.2420050404\#references-section>; Acesso em: out. 2021.

COSTA, A. C. S; PALHETA, A. N. A. A; MENDES, A. M. P; LOUREIRO, A. S. Indústria cultural: revisando Adorno e Horkheimer. Revista Movendo Ideias, v. 8, n. 13, p. 13-22, 2003. Disponível em: <https://repositorio.ufsc.br/bitstream/handle/praxis/467/211.pdf?sequence=1 >; Acesso em: nov. 2021.

ILHARCO, F. A Interculturalidade e as Novas Tecnologias. [In]: Lages, Mário e Teodoro de Matos, Artur. Portugal Intercultural: Razão e Projecto. Lisboa: CEPCEP-UCP e Alto Comissariado para a Integração e Diálogo Intercultural. v. 4, p. 142-184, 2009. Disponível em: <https:/www.yumpu.com/pt/document/read/12850094/v-a-interculturalidade-e-asnovas-tecnologias/10>; Acesso em: dez. 2021.

LEYENS, J. P; PALADINO, P. M; RODRIGUEZ-TORRES, R; VAES, J; DEMOULIN, S; RODRIGUEZ-PEREZ, A; GAUNT, R. The emotional side of prejudice: The attribution of secondary emotions to in-groups and out-groups. Personality and Social Psychology Review, v. 4, n. 2, p. 186-197, 2000. Disponível em: <https://www.researchgate.net/ publication/229060005>; Acesso em: dez. 2021.

LIMA, M. L. P. Atitudes: estrutura e mudança. [In]: J., Vala \& M. B. Monteiro (Eds.). Psicologia Social. (4. ${ }^{a}$ ed, Lisboa: Fundação Calouste Gulbenkian, p. 187-225, 2006.

LIPPMANN, W. Opiniáo Pública [trad. Jacques A. Wainberg] 5a ed. Petrópolis: Rio de Janeiro. Vozes, 2008.

MCLUHAN, M. Understanding Media, Cambridge, Massachusetts, MIT Press, 1994.

NOBRE, A; MOURAZ, A; GOULÃO, M. F; HENRIQUES, S; BARROS, D; MOREIRA, J. A. Processos de comunicaçáo digital no sistema educativo português em tempos de pandemia. Revista Práxis Educacional, v. 17, n. 45, p. 1-19, 2021. Disponível em: <https:// ciencia.iscte-iul.pt/publications/processos-de-comunicacao-digital-no-sistema-educativoportugues-em-tempos-de-pandemia/81354>; Acesso em: dez. 2021.

OTTEN, S; WENTURA, D. About the impact of automaticity in the minimal group paradigm: Evidence from the affective priming tasks. European Journal of Social Psychology, v. 29, n. 8, p. 1049-1074, 1999. Disponível em: <https://www.researchgate.net/ publication/229673636>; Acesso em: nov. 2021.

PERREGIL, E. S; AMANTE, L; BASTOS, G. A interculturalidade e o uso das TIC na educação pré-escolar: Um estudo de caso. Revista Educação em Foco, v. 25, n. 1, p. 13-34, 2020. Disponível em: <https://repositorioaberto.uab.pt/bitstream/10400.2/10205/1/eperrigil_ lamante_gbastos.pdf>; Acesso em: nov. 2021.

RAMALHO, N. A. Processos de globalização e problemas emergentes: implicaçóes para o Serviço Social contemporâneo. Revista Serviço Social \& Sociedade, v. 2, n. 110, p. 345-368, 2012. Disponível em: <https://www.scielo.br/j/sssoc/a/9mQKJNrshQQhky8pmS5b9yB/>; 
Acesso em: out. 2021.

RAMOS, N. Diversidade cultural, educação e comunicação intercultural - políticas e estratégias de promoção do diálogo intercultural. Revista Educação em Questão, v. 34, n. 20, p. 09-32, 2009. Disponível em: <https://repositorioaberto.uab.pt/handle/10400.2/10555>; Acesso em: set. 2021.

RIGOBELlO, L. M. M; FORTUNA, C. M; RIGOBELlO, L. X; PEREIRA, M. J. B; DINIZ, S. A. Revista Latino-Americana de Enfermagem, v. 6, n. 4, p. 95-102, 1998.

Disponível em: <https://www.scielo.br/j/rlae/a/WqWXPyCgNxRNtzBwhLhYmXK/>; Acesso em: dez. 2021.

GUIMARÁES, F. F; FINARDI, K. R. Interculturalidade, internacionalização e intercompreensão: qual a relação? Journal of English Language, Literature in English and Cultural Studies - Ilha do Desterro, v. 71, n. 3, p. 15-37, p. 2018. Disponível em: <https:// www.scielo.br/j/ides/a/rnbLJS9SmZpbg64JLsQ7F9s/>; Acesso em dez. 2021.

SCHAFF, A. A sociedade Informática. São Paulo: Editora Brasiliense, 4a ed, 1995.

STROEBE, W; INSKO, C. A. Stereotypes, prejudice, and discrimination: Changing conceptions in theory and research. [In]: D. Bar-Tal, C. E Grauman, A. W. Kurglanski, \& W. Stroebe (Eds.), Stereotypes and prejudice: Changing conceptions. New York: Springer, p. 3-34, 1989.

VIVANCO, G. Educación y tecnologías de la información y la comunicación jes posible valorar la diversidad en el marco de la tendencia homogeneizadora? Revista Brasileira de Educação, v. 20, n. 61, p. 297-315, 2015. Disponível em: <https://www.scielo.br/j/rbedu/a/ GxsBkwgWG7SHrq34ypqMg6w/>; Acesso em: nov. 2021. 